\title{
Decision Models for the Procurement of Subsidised Air Services
}

\section{Alan Kinene}

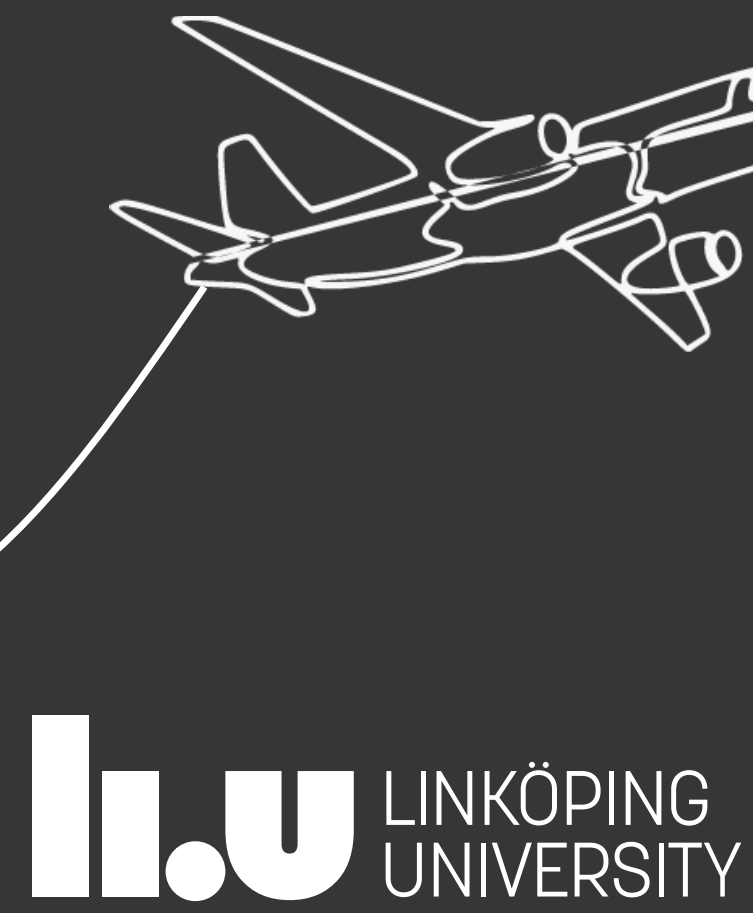





\title{
Decision Models for the Procurement of Subsidised Air Services
}

\author{
Alan Kinene
}

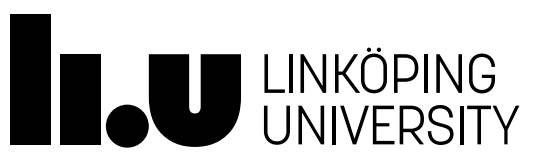

Linköping University

Department of Science and Technology

Division of Communication and Information Systems

SE-601 74 Norrköping, Sweden

Linköping 2021 
This is a Swedish Licentiate's Thesis

Swedish postgraduate education leads to a doctor's degree and/or a licentiate's degree. A doctor's degree comprises 240 ECTS credits (4 years of full-time studies). A licentiate's degree comprises 120 ECTS credits.

(c) EY-No This work is licensed under a Creative Commons AttributionNonCommercial 4.0 International License.

https://creativecommons.org/licenses/by-nc/4.0/

(C) Alan Kinene, 2021

ISBN 978-91-7929-703-9

ISSN 0280-7971

Published articles have been reprinted with permission from the respective copyright holder.

Printed by LiU-Tryck, Linköping, Sweden 2021 


\begin{abstract}
Small communities or remote regions are usually ignored by airlines because they have insufficient passenger demand and the air services to and from these regions are unprofitable. Free market conditions would lead to the lack of air connectivity to and from remote regions, hence transportation authorities intervene by procuring air services to guarantee improved accessibility for these regions. The procurement of air services is done through subsidy schemes where the transportation authorities pay subsidies to airlines that provide these air services along the routes to and from remote regions. These routes are commonly referred to as subsidised routes.

The procurement of subsidised air services (subsidised routes) involves two major tasks-the selection of routes to subsidise and the selection of airlines to serve these routes. These are the focus of this thesis. The overall aim of this thesis is to design decision support models that can be used by transportation authorities to select the routes to subsidise and to select airlines to serve these routes.

First, we develop an optimisation model that selects the routes to be subsidised, by maximising the number of people that can reach a given destination under different accessibility criteria subject to a budget. The model is capable of handling multiple accessibility criteria. As input to this model, we develop a novel method for estimating the subsidies required for non-existing subsidised routes.
\end{abstract}

Second, we develop an auction framework to provide decision support to transportation authorities when designing auctions for the procurement of subsidised air services. The auction framework has three steps: auction definition by the transportation authority, bid preparation by the bidding airlines, and winner determination by the transportation authority. We develop two optimisation models as part of the auction framework, a winner-determination model for selecting the bids with the minimum subsidies, and a bid preparation model that replicates the airline's behaviour when preparing bids for subsidised routes. The bid preparation model has an objective of minimising subsidies subject to a minimum profit threshold. We additionally propose models to estimate the appropriate demand and the route-operation cost for subsidised routes, which are needed as input to the bid preparation model.

We demonstrate the usefulness of the two decision support models using the Public Service Obligation (PSO) network of subsidised routes in Sweden. The results suggest that the optimisation model can be used to select a new network of subsidised routes with improved accessibility to given destinations (e.g., the capital and an international airport) at a lower subsidy cost than the current network of subsidised routes. Having a requirement on the maximum airfare but not the minimum number of flights provides a good trade-off between the current restrictive setup with requirements on both the minimum number of flights and the maximum airfare, and a setup of the tendering process with no restrictions. 



\section{Acknowledgements}

Throughout the writing of this thesis, I have received a great deal of support and assistance.

First, I would like to thank my main supervisor Tobias Andersson Granberg and co-supervisors Valentin Polishchuk and Clas Rydergren for their insightful feedback and guidance. Working with you has been a remarkable learning experience.

I would like to thank the Swedish Transport Administration (Trafikverket) for funding my Ph.D. studies through the SAILAS project. The members of the reference group for the SAILAS project have greatly assisted with the shaping of this thesis work. These include Anna Norin from Swedavia, Andreas Holmgren from Transportstyrelsen, Johan Holmer from Trafikverket, and Billy Josefsson and Per Bertler from LFV. Special thanks to Jean-Marie Skoglund, Håkan Jacobsson and Bosse Andersson from Trafikverket for continuously providing all the information I have requested for.

In addition, I would like to thank my co-authors Nicole Adler and Sebastian Birolini for the opportunity learn from them.

I would like to thank my colleagues at the division of Transportation Systems (KTS), specifically, Viveka Nilson for all the help with the administration tasks, and Scott Fowler for the wide range of chats. I would also like to thank my fellow PhD students Niki, Nikolaos, Antzela, Therese, Nils, Manos, Christian, Leo, Marcos, Yannis, Viktor, Tomas, and Joen for their company.

My partner Catherine, I appreciate your interest in my work, your encouragement and advice. In a special way, I would like to thank my sisters (Justine, Grace, and Lillian) and parents Rose and James Mukiibi for the unconditional support.

Finally, I could not have completed this thesis without the support of my friends from Uganda and Örebro, and Norrköping CrossFit Community who have provided happy distractions to rest my mind outside of my research. 


\section{Contents}

$\begin{array}{lll}\text { Abstract } & \text { iii }\end{array}$

Acknowledgments $\quad$ v

Contents vi

List of Figures viii

$\begin{array}{ll}\text { List of Tables } & \text { ix }\end{array}$

List of Abbrevations $\quad$ xii

1 Introduction 1

2 Procurement of Air Services in Subsidy Schemes 3

2.1 Subsidy Schemes . . . . . . . . . . . . . . . . 3

2.2 The Stages in the Procurement of Air Services . . . . . . . . . 5

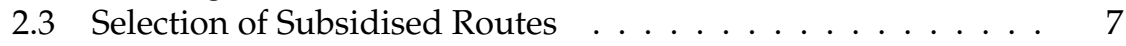

2.4 Auction for Subsidised Routes . . . . . . . . . . . . . . . . 9

3 Models for Procuring Subsidised Routes 13

3.1 Models for Selecting Subsidised Routes . . . . . . . . . . . . 13

3.2 Designing an Auction for Subsidised Routes . . . . . . . . . 15

3.3 Required Data . . . . . . . . . . . . . . . . . . . . . . . 18

3.4 Output of the Decision Models . . . . . . . . . . . . . 19

4 Goals, Contributions, and Publications 21

4.1 Research Questions and Goals . . . . . . . . . . . . . . . 21

4.2 Contributions . . . . . . . . . . . . . . 22

4.3 Summary of the Papers . . . . . . . . . . . . . . . 22

4.4 Discussion and Future Research . . . . . . . . . . . . . . 24

$\begin{array}{ll}\text { Bibliography } & 27\end{array}$

$\begin{array}{ll}\text { Paper I } & 33\end{array}$ 
Paper II 


\section{List of Figures}

2.1 The stages in the procurement of air services in subsidy schemes 5

2.2 Investigation of the need for a subsidy scheme based on accessibility 8

2.3 The tendering process for subsidised routes based on an example from the Swedish PSO tendering period 2015-2019 . . . . . . . 9 


\section{List of Tables}

2.1 A description of the four categories of existing subsidy schemes and examples of implementing countries . . . . . . . . 4 4

2.2 The eight criteria used in Sweden. Each criterion is further described by specific targets a (good) or $b$ (acceptable). . . . . . . 6

3.1 Components of a base model for selecting subsidised routes . . . 14

3.2 Components of a base model for the preparation of a bid to serve regions in a bundle . . . . . . . . . . . . 17

3.3 Components of a base model for the determination of winners by

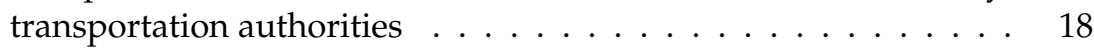





\title{
List of Abbreviations
}

\author{
EAS Essential Air Services \\ EEA European Economic Area \\ O-D Origin-Destination \\ PSO Public Service Obligation \\ SEK Swedish Krona
}

U.S. DOT United States Department of Transportation

WDP Winner Determination Problem 



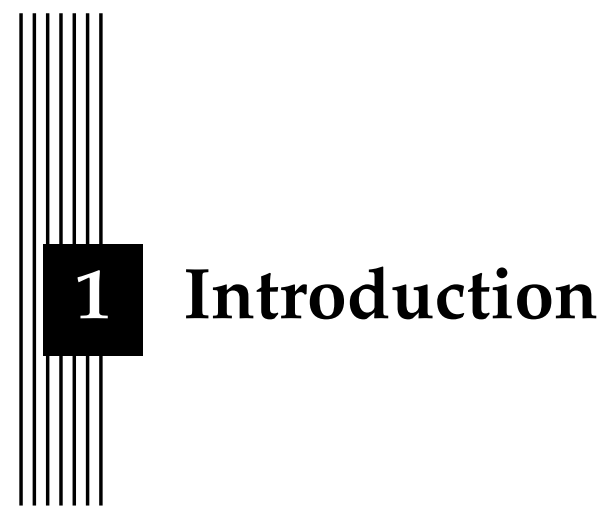

Air transportation enables economic growth and development through facilitation of connectivity on a national and international scale. The commercial transportation of people by airlines-also known as passenger trafficstarted in 1914, and in 1926, governments began regulating it to create market stability. The governments controlled route entry and exit of the airlines, regulated airfares, and awarded subsidies to airlines that operated unattractive routes. As the number of passengers and routes grew, the regulation became inefficient: some airlines with monopolistic practices inflated airfares and there were barriers to entry for new airlines. Therefore, governments decided to deregulate air transportation-1978 in the United States (U.S.) and 1987 in Europe-such that the airlines could freely choose new profitable routes, abandon/ignore the unprofitable routes, and choose airfares.

The airlines ignore the routes that serve remote regions if they have insufficient passenger demand and they are unprofitable, which is usually the case (Morrison et al., 2010; Williams and Bråthen, 2012). The abandonment of these routes by profit-oriented airlines leads to lack of air connectivity to and from remote regions (Anger et al., 2016). Thus, deregulation impairs accessibility ${ }^{1}$ of people in small communities or remote regions to and from given destinations, e.g., a major city, a hospital, and a hub or an international airport within a specified travel time.

${ }^{1}$ Accessibility can, for example, be measured as the ability of people from an origin to reach activities in desired destinations, usually within a specified travel time (Litman, 2020). 
Because of the lack of air connectivity to and from small communities or remote regions, transportation authorities in Europe, the U.S., Asia, and Australia procure air services to guarantee improved accessibility to these regions. The procurement of air services is done within subsidy schemes where the transportation authorities pay subsidies to airlines that provide these air services along the routes to and from remote regions. These routes are commonly referred to as subsidised routes. The procurement of subsidised air services, or simply the procurement of subsidised routes, involves two major tasks: it begins with the selection of routes to subsidise, followed by the selection of airlines to serve these routes (see Trafikverket (2017)). The airlines are selected through an auction/tender between the transportation authority and the airlines, where the latter submits sealed bids for operating a specific route or set of routes. The selected airlines receive subsidies from the transportation authority for serving the subsidised routes. These two tasks influence the subsidies spent by transportation authorities on subsidised routes and the efficient use of the subsidy schemes to improve accessibility to and from the small communities or remote regions.

For the past two decades, the subsidies spent by transportation authorities on subsidised routes have increased (Gössling et al., 2017; DoT U.S., 2009). Additionally, there is criticism regarding misuse of subsidised schemes, for example selecting routes that do not meet the criteria for subsidised routes, which leads to high levels of redundant routes (Lian et al., 2010; Fageda et al., 2018). The designing of an auction for the selection of airlines to serve subsidised routes is a crucial and hard task because the transportation authorities consider multiple requirements, for example, the minimum level of service and the maximum airfares, which affect the subsidies paid by the transportation authorities. Therefore, there is a need for good decision support tools to assist the transportation authorities when procuring subsidised air services, for example concerning minimising subsidies. The elimination of redundant routes and the designing of an auction with appropriate requirements would minimise the misuse of subsidised routes and reduce the subsidies.

The overall aim of this thesis is to design decision support models that can be used by transportation authorities to select the routes to subsidise and to design auctions with appropriate requirements for these routes.

The remaining chapters of the thesis are as follows. Chapter 2 has an overview of the procurement process for subsidised routes with a focus on the two sub-problems involved-the selection of routes to subsidise and the design of an auction for selecting airlines to serve these routes. Chapter 3 includes the formulation of models related to the two sub-problems. In Chapter 4 , we present the aim, research questions, goals, contributions of the thesis, and a summary of the included papers. We conclude the chapter with a discussion of the two included papers and directions for future research. 


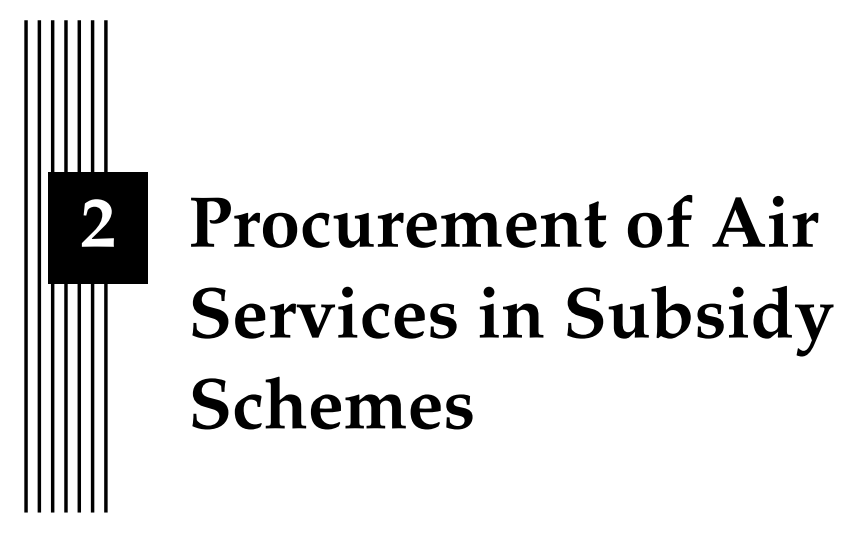

In this chapter, we present an overview of the procurement of subsidised routes. The chapter begins with Section 2.1 that describes what subsidy schemes are and gives a description of the four major categories of existing subsidy schemes. In Section 2.2, we discuss the three main stages in the procurement of air services in subsidy schemes. This thesis focuses on two of the stages - the selection of routes to subsidise and the design of an auction for selecting airlines to serve these routes-and they are further described in Section 2.3 and 2.4 using examples from Sweden.

\subsection{Subsidy Schemes}

A subsidy scheme is an economic intervention that extends any form of financial aid or in-kind support to virtually all sectors (Gössling et al., 2017). In air transportation, transportation authorities use subsidy schemes as a response to the lack of air connectivity to and from small communities or remote regions. The overall purpose of these subsidy schemes is to guarantee air connectivity to and from eligible communities with insufficient demand for commercial air services. Countries use various terms to describe an eligible community for subsidy schemes: remote regions, small communities, isolated communities, and non-commercially viable routes (Fageda et al., 2018; Williams and Bråthen, 2012). In this work, we use these interchangeably because all the subsidy schemes aim to guarantee air connectivity to and from 
small communities or remote regions with insufficient demand for commercial air services.

Generally, the existing subsidy schemes can be divided into four categories: route-based, passenger-based, airline-based, and airport-based schemes-see Table 2.1 for details. Some countries may have a combination of these schemes. For example, the U.S. and some European Economic Area (EEA) countries, such as Sweden and Norway, have both route-based schemes and airport-based schemes (Fageda et al., 2018).

Table 2.1: A description of the four categories of existing subsidy schemes and examples of implementing countries

\begin{tabular}{lll}
\hline Subsidy scheme & Description & $\begin{array}{l}\text { Example of implementing } \\
\text { countries }\end{array}$ \\
\hline Route-based policies & $\begin{array}{l}\text { This is the most widely used subsidy scheme and } \\
\text { it has been implemented in countries where air } \\
\text { transportation is fully deregulated. It imposes a } \\
\text { service obligation (e.g. a number of daily flights, } \\
\text { maximum airfare and monopoly rights) on } \\
\text { specific routes. }\end{array}$ & $\begin{array}{l}\text { Australia, Chile, European Union, } \\
\text { Norway, Malaysia, Peru, } \\
\text { the United States, India }\end{array}$ \\
\hline & $\begin{array}{l}\text { Governments give discounts to residents, which } \\
\text { may be included in route-based policies. These } \\
\text { discounts may either be an absolute value or a } \\
\text { percentage of the market airfare. }\end{array}$ & $\begin{array}{l}\text { Ecuador, Portugal, Scotland, } \\
\text { Spain }\end{array}$ \\
\hline Airline-based policies & $\begin{array}{l}\text { Governments give financial assistance to } \\
\text { airlines-usually state-owned-to support } \\
\text { air services to remote regions. }\end{array}$ & $\begin{array}{l}\text { Bolivia, Canada, Colombia, } \\
\text { Ecuador, Malaysia }\end{array}$ \\
\hline Airport-based policies & $\begin{array}{l}\text { Airports receive subsidies for airport programs } \\
\text { such as expanding and improving infrastructure } \\
\text { capacity. These policies also include incentives } \\
\text { (e.g., airport-fees discounts) that are channelled } \\
\text { through airports to airlines, to launch new routes. }\end{array}$ & $\begin{array}{l}\text { Australia, Brazil, Canada, } \\
\text { European Union, } \\
\text { the United States }\end{array}$ \\
\hline Source: Adapted from Fageda et al. (2018) & \\
\hline
\end{tabular}

This chapter focuses on the most studied category of subsidy schemes in the literature-the route-based subsidy schemes (Fageda et al., 2018). These subsidy schemes are implemented as short-term contracts of 2 to 5 years between governments and airlines. The contracts may specify the service levels/requirements that include: flight frequencies, aircraft type, flight schedules, and route airfares. The governments pay a subsidy (per route) to the airlines for meeting these service requirements. Furthermore, the two major route-based subsidy schemes in terms of the number of routes and the amount of subsidies spent are the Public Service Obligations (PSOs) in the EEA and the Essential Air Services (EAS) in the U.S.

In the EEA, a member state autonomously decides how to impose a PSO on routes that are crucial for economic-social development of a (peripheral) region (EU Regulation, 2008). The PSO is intended to ensure that the provided air services satisfy fixed standards of continuity, regularity, pricing, and minimum capacity that would not be realised if airlines were to commercially assess the routes. In the U.S., the Office of the Secretary of the U.S. Department of Transportation (U.S. DoT) administers the EAS: it aims 
to guarantee that small communities that had air services before deregulation, maintain a link to the national airport network with a minimum level of scheduled air services (DoT U.S., 2009). Although the decisions of how to impose a PSO on routes or how to administer the EAS to small communities may somewhat differ, the PSO, the EAS, and other subsidy schemes aim to achieve two main objectives: (1) to guarantee air services to/from regions with low accessibility, and (2) to guarantee a connection of all regions to the national air transportation system.

\subsection{The Stages in the Procurement of Air Services}

Procurement is the act of buying goods and services: it consists of all the activities necessary to acquire goods and services that are consistent with defined requirements (Novack et al., 1991). Each country's transportation authority is in charge of the procurement for subsidy schemes with a target to guarantee sufficient and satisfactory provision of transport services to all regions in a country. The procurement of air services in subsidy schemes can be summarised in three stages as shown in Figure 2.1.

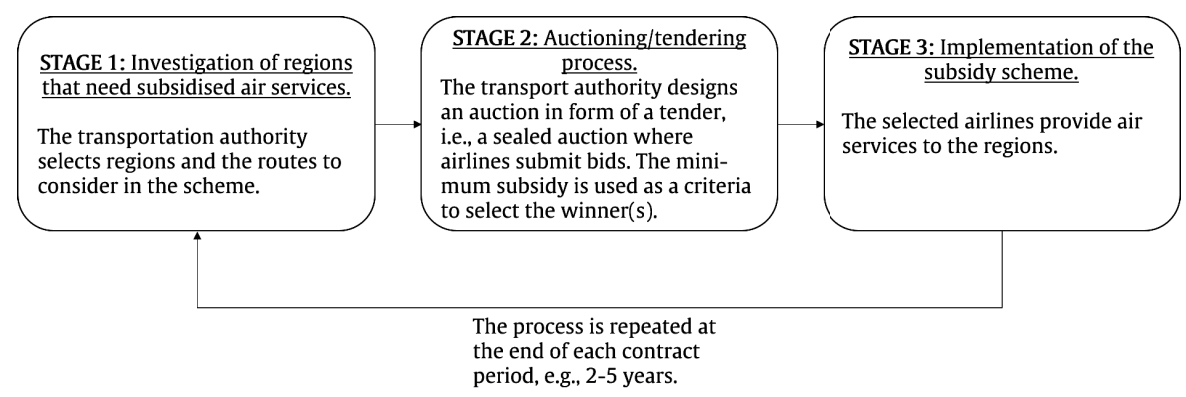

Figure 2.1: The stages in the procurement of air services in subsidy schemes

For subsidy schemes, the procurement of air services begins with an investigation, where the transportation authority identifies regions to benefit from the subsidy scheme, and consequently, selects routes to subsidise. Typically, the transportation authority assesses the need for subsidised routes by regions based on defined accessibility criteria to certain destinations, for example, a major city, advanced hospital, a hub or an international airport, a university, or a tourist site. The criteria are also defined by specific timerelated targets. For example, it should be possible to access a capital city within four hours. The regions that lack access to these destinations would be considered as candidates for the subsidy scheme. There are variations in how the transportation authorities in different countries define these accessibility criteria but they all aim to assess economic, social and territorial cohesion. Table 2.2 gives an example of the eight accessibility criteria used 
by the Swedish Transport Authority (Trafikverket) to assesses the need for subsidised routes to and from 290 municipalities (Trafikverket, 2017).

Table 2.2: The eight criteria used in Sweden. Each criterion is further described by specific targets a (good) or b (acceptable).

\begin{tabular}{|c|c|c|}
\hline Criteria & Description & Target \\
\hline 1. To Stockholm & $\begin{array}{l}\text { Reach central Stockholm } \\
\text { during the day }\end{array}$ & $\begin{array}{l}\text { a. Within } 4 \text { hours } \\
\text { b. Within } 5 \text { hours }\end{array}$ \\
\hline 2. From Stockholm & $\begin{array}{l}\text { Travel from Stockholm } \\
\text { to the municipality }\end{array}$ & $\begin{array}{l}\text { a. Within } 4 \text { hours } \\
\text { b. Within } 5 \text { hours }\end{array}$ \\
\hline $\begin{array}{l}\text { 3. International } \\
\text { travel }\end{array}$ & $\begin{array}{l}\text { Possibility of international air travel } \\
\text { by arriving at any of Stockholm-Arlanda, } \\
\text { Gothenburg-Landvetter, Copenhagen-Kastrup, } \\
\text { Oslo-Gardermoen and Trondheim-Vaernes } \\
\text { airports on weekdays }\end{array}$ & Travel time is not specified \\
\hline 4. Major cities & $\begin{array}{l}\text { Accessibility to Stockholm, Gothenburg, } \\
\text { Malmö, Sundsvall, Umeå, Luleå, Linköping, } \\
\text { Copenhagen, Oslo or Trondheim }\end{array}$ & $\begin{array}{l}\text { a. Within } 4 \text { hours to at least } 1 \\
\text { city } \\
\text { b. Within } 5 \text { hours to at least } 1 \\
\text { city }\end{array}$ \\
\hline $\begin{array}{l}\text { 5. Regional/University } \\
\text { hospital }\end{array}$ & $\begin{array}{l}\text { Accessibilty to a university or a regional } \\
\text { hospital in Umeå, Stockholm, Uppsala, } \\
\text { Örebro, Linköping, Gothenburg, Malmö } \\
\text { and Lund }\end{array}$ & $\begin{array}{l}\text { a. Within } 3 \text { hours } \\
\text { b. Within } 4 \text { hours }\end{array}$ \\
\hline $\begin{array}{l}\text { 6. University and } \\
\text { higher education }\end{array}$ & $\begin{array}{l}\text { Accessibility to higher education } \\
\text { in } 23 \text { municipalities }\end{array}$ & $\begin{array}{l}\text { a. Within } 5 \text { hours to at least } 10 \\
\text { target municipalities } \\
\text { b. Within } 5 \text { hours to at least } 5 \\
\text { target municipalities }\end{array}$ \\
\hline 7. Other major cities & $\begin{array}{l}\text { Accessibility to a municipality } \\
\text { with at least 50,000 inhabitants }\end{array}$ & $\begin{array}{l}\text { a. Within } 3 \text { hours to at least } 3 \\
\text { target municipalities } \\
\text { b. Within } 4 \text { hours to at least } 2 \\
\text { target municipalities }\end{array}$ \\
\hline 8. Tourism & $\begin{array}{l}\text { The possibility for the rest of } \\
\text { the country to reach an essential } \\
\text { population center in the municipality }\end{array}$ & $\begin{array}{l}\text { a. } 50 \% \text { of the Swedish population } \\
\text { reaches the population center } \\
\text { within } 5 \text { hours } \\
\text { b. } 50 \% \text { of the Swedish population } \\
\text { reaches the population center } \\
\text { within } 7 \text { hours }\end{array}$ \\
\hline
\end{tabular}

Source: Trafikverket (2017)

The second stage in the procurement of air services in subsidy schemes is the design of the tendering process. In this stage, the transportation authority needs to design tendering agreements for the provision of air transportation 
services to the selected regions in the first stage. The tendering agreements are used by the transportation authorities in the call for tenders to airlines to operate subsidised routes. The agreements include requirements to be fulfilled by the airlines. These requirements should be determined by the transportation authority such that they harmonise the interests of all stakeholders (i.e., the transportation authority, the airlines, and the passengers). Commonly used requirements in the tendering process are: (1) minimum number of round trips per day; (2) minimum seat capacity per day; (3) maximum number of stops; (4) time table requirements, for example, a maximum number of days per year with no service; (5) size of aircraft; (6) air emissions of specified substances; and (7) maximum one-way ticket fares (Williams and Bråthen, 2012). Airlines respond to the call for tenders by submitting sealed bids for bundles of combinations of routes from which the transportation authority chooses the best bid for each subsidised route. This stage concludes with the signing of a tendering agreement or contract period-usually ranging from 2 to 5 years.

After the transportation authority designs the tendering process and selects airlines to serve the subsidised routes, the third stage is the implementation of the subsidy scheme. Here, the airlines provide air services to the regions based on the tendering agreements. The transportation authority monitors the essential terms of the tendering agreements, e.g, number of flights, and resolves any possible discontinuation of air services by the airlines. This stage lasts until the conclusion of the tendering agreement or contract period, after which the procurement is repeated.

The first two stages of the procurement for air services in subsidy schemes-i.e., the selection of routes to subsidise through an investigation of the need for a subsidy scheme, and the design of the tendering process for selecting airlines to serve these routes-directly affect the efficient use of subsidised schemes and the subsidies paid by the transportation authorities. Therefore, the next two sections of this chapter focus on these two stages to help the transportation authorities to respond to criticisms regarding misuse of subsidy schemes, i.e., selecting routes that do not meet the criteria for subsidised routes and the continuously increasing subsidies spent by transportation authorities.

\subsection{Selection of Subsidised Routes}

In this section, we describe the first stage where the transportation authority must investigate the regions' need for subsidised air services, and also present previous research related to this.

The investigation of the need for subsidised air services is done by the respective country's transportation authority through an accessibility analysis of all the country's regions based on defined criteria. The regions with a defi- 


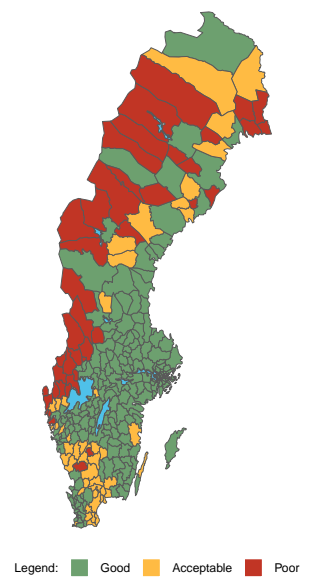

(a) Accessibility without subsidised routes

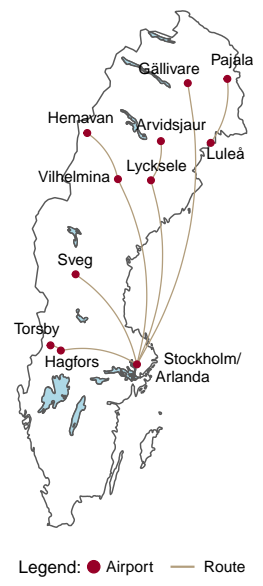

(b) Possible subsidised routes

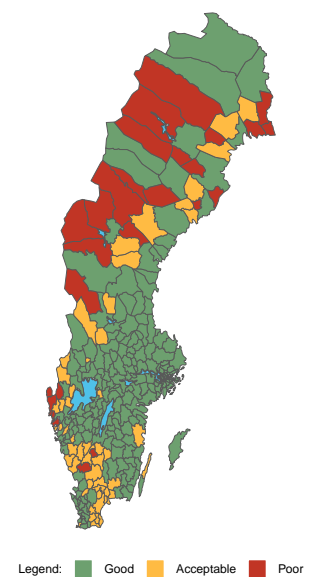

(c) Accessibility with subsidised routes $(a+b)$

Figure 2.2: Investigation of the need for a subsidy scheme based on accessibility

ciency in accessibility would qualify to have subsidised routes. The selection of routes for the subsidy scheme should be within the available budget.

To further elaborate on this, we use an example from Sweden, specifically the accessibility criterion to Stockholm. The Swedish Transport Authority (Trafikverket) assesses the need for subsidised routes to and from all $290 \mathrm{mu}-$ nicipalities based on the eight accessibility criteria in Table 2.2. Trafikverket analyses the accessibility of the people in each municipality to each criterion's destination. This is done in two parts.

First, it analyses accessibility in a situation without the subsidised routes. This analysis would for example result in a map as in Figure 2.2a, which presents the accessibility using ground transportation and existing commercial flights, i.e., without any subsidised routes. The analysis is used to identify the municipalities with good (green colour) accessibility, those with acceptable (yellow colour) accessibility, and most importantly those with poor (red colour) accessibility to Stockholm. Secondly, Trafikverket selects possible subsidised routes both with a stop and without a stop (see Figure 2.2b) to provide scheduled air transportation services to some of the red-coloured municipalities. This is done to improve the accessibility to Stockholm for some of the municipalities with poor (red colour) accessibility, i.e., to either good (green colour) or acceptable (yellow colour) accessibility (see Figure 2.2c). The accessibility with air services considers the concerned airport(s) catchment area, that is the geographic area from which its users are expected to originate from. This implies that not all people from the municipality are 
expected to have the same accessibility for all the eight accessibility criteria. Additionally, Trafikverket has a limited budget, which should be considered when selecting subsidised routes.

\subsection{Auction for Subsidised Routes}

In this section, we use Figure 2.3 to describe the second stage from Figure 2.1 where the transportation authority carries out an auction in form of a tender (sealed bid auction) to select an airline to provide air services to remote regions. Figure 2.3 represents the tendering process of subsidised routes in Sweden for the tendering period of 2015 to 2019.

1. The transportation authority invites airlines to tender for the provision of air services to remote regions. It specifies the requirements per region.
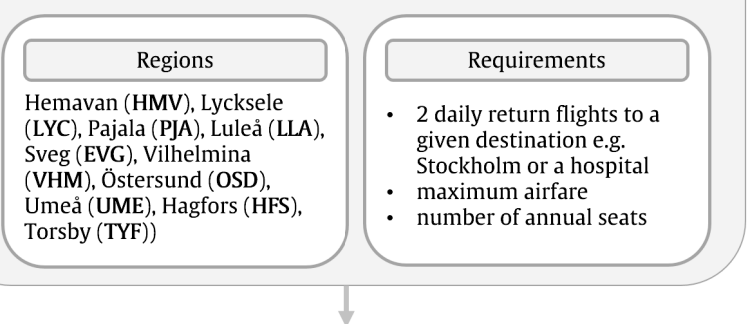

2. The airlines submit multiple sealed bids to the transportation authority. Each bid can include a single region or a combination of multiple regions
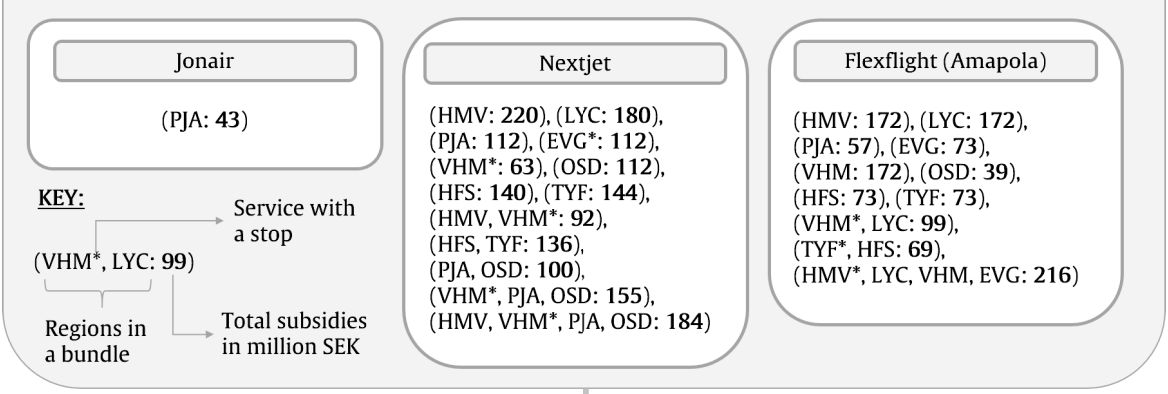

$$
\begin{aligned}
& \text { 3. The transportation authority selects the bids } \\
& \text { that require the minimum subsidies: } \\
& \text { Flexflight: (TYF*, HFS: 69), (OSD: 39), (EVG: 73) } \\
& \text { Nextjet: (HMV, VHM*: 92), (LYC: 180), } \\
& \text { Jonair: (PJA: 43) }
\end{aligned}
$$

Figure 2.3: The tendering process for subsidised routes based on an example from the Swedish PSO tendering period 2015-2019

After the selection of subsidised routes to serve remote regions (see Figure 2.3), the transportation authority needs to find airlines willing to offer 
air services along these routes. This is done through an auction/tendering process. A tender is a special form of auction where buyers (sellers) submit sealed bids to the seller (buyers) who then selects the winning bids. The tendering process for subsidised routes is illustrated using an example in Figure 2.3, which is based on the subsidy scheme in Sweden.

First, the tendering process begins with the transportation authority inviting airlines to tender for the provision of air services to remote regions. The invitations to tender are published on official sites, for example, the official journal of European Communities. Sometimes the tenders are defined concerning an airport serving a remote region (e.g., Vilhelmina municipality), while other times, as in Figure 2.3, it is defined in terms of airports (e.g., Vilhelmina airport (VHM)). Also, the transportation authority needs to determine the required level of service for each region. For example, in Sweden, Trafikverket states these requirements: 2 round trips per day for 6 days a week, maximum airfare, minimum number of seats per year, and the aircraft cabins should be pressurised.

Second, the airlines submit multiple sealed bids to the transportation authority. The bids are in form of bundles, i.e., a set of regions (or routes serving regions). Each bundle could include a single route to provide air services to a remote region or multiple routes to provide air services to multiple remote regions (see Step 2 in Figure 2.3). Additionally, each of the bundles is associated with an amount of subsidies required by the airline to provide air services to the associated regions.

Third, the transport authority selects one airline for each region based on an evaluation criterion, usually minimum subsidies. The airline receives a contract that states the expected subsidies-which takes into account the operation cost and revenue generated by the air services-from the transportation authority. For the example in Figure 2.3, Trafikverket selected the bids that cost 496 million SEK for the whole contract period of 2015 to 2019 (Trafikverket, 2013).

The design of the tendering process affects the airlines' participation in the tender and amount of subsidies paid by the transportation authority. For example, airlines in Europe have emphasised the strict nature of the PSO requirements as a major factor that reduces their freedom and discourages their participation in the tendering process (Williams and Bråthen, 2012). Consequently, the number of biding airlines is worryingly declining in every successive tendering period. For example, in Sweden, the number of bids per route was 4 in the 2002-2004 contract period but reduced to 2 in the 2015-2019 contract period (Dahlström et al., 2018). Furthermore, the subsidised routes in Europe (PSO routes) have been characterised by discontinuous services: several carriers pulled out of their contracts prematurely because of underestimated operational costs for the contracted routes. In some cases, the tender-winning carrier entered into bankruptcy before the end of the contract (Williams and Pagliari, 2004). For example, Sweden's NextJet 
airline that won the PSO tender illustrated in Figure 2.3 went bankrupt in 2017-2 years before the end of the contract (Dahlström et al., 2018). This is also attributed to the miss-match of stakeholders' interests represented by the PSO requirements, i.e., transportation authority want to minimise subsidies, airlines want to maximise profit, and the passengers want frequent flights at cheap airfares. 



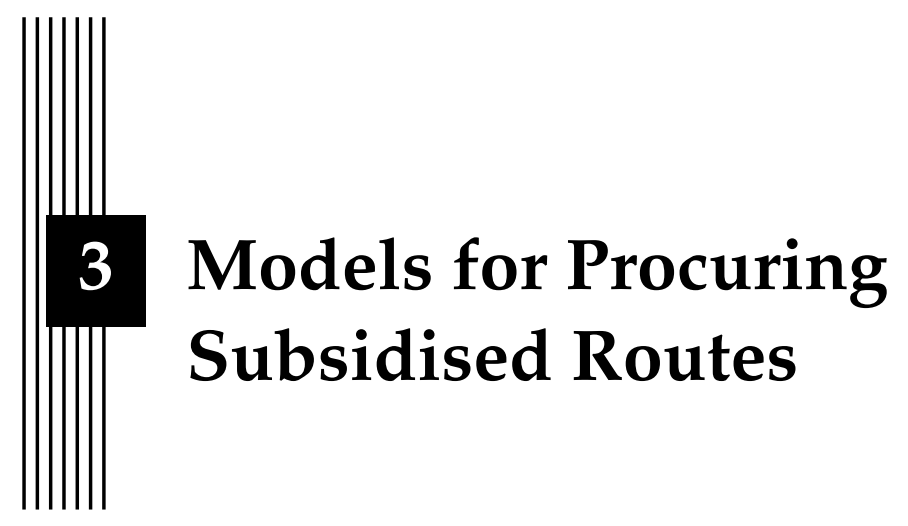

In this chapter, models for the selection of subsidised routes and the design of the tender process for subsidised routes are presented. The focus is on models that can help decision-makers when procuring subsidised routes by objectively assessing the implications of pursuing different alternatives. These models should help transportation authorities with the two major stages in the procurement of air services-selection of routes that need subsidised air services and the auctioning process for subsidised routes.

\subsection{Models for Selecting Subsidised Routes}

Previous studies, for example, Flynn et al. (1988) and Matisziw et al. (2012), have discussed optimisation models for the selection of subsidised routes. Optimisation models aim to either maximise (e.g., accessibility) or minimise (e.g., cost) subject to certain constraints. These studies focused on the effectiveness of subsidised routes in terms of improving accessibility and the minimisation of subsidies paid by transportation authorities. Accessibility can be evaluated based on either distance (see Flynn et al. (1988)) or travel time (see Matisziw et al. (2012)) from an origin to a target destination. As illustrated by Matisziw et al. (2012), travel time gives a more appropriate measure of accessibility than distance.

The selection of routes to subsidise can be formulated as an optimisation model, specifically as a budgeted maximal covering model. Given the the accessibility criteria (e.g., those in Table 2.2), the transportation authority 
needs to select routes to subsidise to improve the people's accessibility from the regions that can not reach a certain destination within a target time. The transportation authority needs to select routes that ensure accessibility for as many people as possible subject to a budget.

A model for selecting subsidised routes can be formulated as follows. The whole population $P$ is be grouped into population centres $p$ and each centre $p \in P$ has a weight $D_{p}$ corresponds to the centre's population. The transportation authority considers a set $F$ of all possible subsidised routes that are obtained as combinations of maximum two population centres. Each route $f \in F$ provides accessibility to a subset of population centres, i.e., there is a subset $P_{f} \subseteq P$ that is served by route $f$ with in a target time. The base model has the four components as presented in Table 3.1.

Table 3.1: Components of a base model for selecting subsidised routes

\begin{tabular}{ll}
\hline 1. Objective. & $\begin{array}{l}\text { Maximise the accessibility, i.e, number of people } \\
\text { that can reach a given destination within a } \\
\text { given time. }\end{array}$ \\
2. Decision variables. & $\begin{array}{l}\text { Whether route } f \text { is selected }\left(x_{f}=1 \text { or } 0\right) . \\
\text { Whether centre } p \text { is served by a selected } \\
\text { route }\left(y_{p}=1 \text { or } 0\right) .\end{array}$ \\
3. Input parameters. & $\begin{array}{l}\text { The number of people at centre } p\left(D_{p}\right) . \\
\text { A }|P| \times|F| \text { matrix } A \text { with entry } A_{p f}=1 \text { or } 0 \\
\text { depending on whether route } f \text { provides a way } \\
\text { to reach the destination from centre } p \text { within }\end{array}$ \\
& a given time or not. \\
The cost of subsidising route $f$. & A given budget $B$.
\end{tabular}

The optimisation models developed by Flynn et al. (1988) and Matisziw et al. (2012) were more extensive than our base model. Flynn et al. (1988) also employed a maximal covering model but simultaneously maximised population coverage and minimised cost. Their model was capable of identifying the best type of service for each community: continued service, discontinued service, and increased service. Flynn et al. (1988) only modelled the existing subsidy schemes (i.e., the EAS), which leads to an interesting research gap concerning how to model a non-existing subsidy system. Flynn et al. (1988) added a stopover service option in the model to permit the evaluation of potential gains in economic efficiency based on operation cost, and they recommended an expansion of their model to accommodate a multimodel network with both air and ground transportation. Matisziw et al. (2012) developed a bi-objective optimisation model—simultaneously minimising hub-access cost and maximising community accessibility. They used their model to suggest an optimal network of subsidised routes, which they compared to the existing subsidy system. Matisziw et al. (2012) tried to ad- 
dress the gap in Flynn et al. (1988)'s work by modelling a non-existing network but focused on minimising the the passengers' travel time and cost of subsidisation, which is also of interest to the transportation authority.

Our model is extended to consider other aspects. For example, with a constraint that ensures that a population centre should not have a subsidised route if there is a possibility of using either an existing commercial flight or ground transportation within the considered target time. Furthermore, as it may be beneficial to assess the accessibility to more than one destination, i.e., multiple accessibility criteria, the model, specifically the objective function, could be modified to accommodate multiple accessibility criteria.

\subsection{Designing an Auction for Subsidised Routes}

An auction is a market institution with well-defined rules that determine the winner and prices of items based on received bids from market participants (Milgrom et al., 1982; McAfee et al., 1987; Mochón et al., 2015). The items sold at auctions include goods, such as artwork and books, and services such as the provision of subsidised air services. Auctions are useful in absence of a standard value for an item and when the seller is unsure about what it should be: auctions discover its value (McAfee et al., 1987; Vijay, 2015). In the procurement of subsidised routes, which is the focus of this work, the government does not know how much it should pay airlines for their services along subsidised routes. Therefore, the government uses an auction to discover the subsidy cost of air services along subsidised routes and to select airlines to provide these services.

Auctions can be classified into four basic types based on how the winning price is determined (i.e., single or multiple auction rounds), and the price paid by the winner (McAfee et al., 1987; Vijay, 2015):

1. The English auction (ascending-bid auction). The auctioneer successively increases the price until only one bidder remains. The sellers commonly use it to sell goods to maximise price. It has multiple rounds, and the auctioneer openly communicates the current best price to each bidder.

2. The Dutch auction. It is the converse of the English auction: it starts with a high price, which the auctioneer successively lowers until one bidder accepts the given price.

3. The first-price sealed-bid auction. The bidders submit sealed bids, and the auctioneer awards the item to the highest bidder for the same price that he bid. Unlike in the English auction, here, bidders are not able to observe other bidders' bids. This is common in government procurement of public service contracts. 
4. The Vickrey sealed-bid (second-price) auction. The highest bidder wins the item but pays the price equal to the second-highest bid (Vickrey, 1961). Although Vickrey auctions are rarely used in practice, they encourage more truthful bidding and have higher expected revenue than first-price auctions.

There are variations of these four basic - traditional-auctions. First, as the word auction can be used to describe both offerings to sell and bids to buy, an auction can either be forward or reverse (McAfee et al., 1987). A forward auction is used to get the highest price (i.e., when offering to sell) while its converse, a reverse auction, is used to get the lowest price (i.e., when bidding to buy) as in government procurements (Mochón et al., 2015). Secondly, based on the number of items, the simplest auction form has a single unique indivisible item to be sold to one-out-of-many potential buyers (Vickrey, 1961). Having multiple items leads to multi-item auctions. If the items are related, that is substitutes and/or complements, a type of multiitem auctions known as combinatorial auctions are recommended (Mochón et al., 2015; Biswas et al., 2005; Pikovsky, 2008), as they allow bidders to exploit the relationships between items. Auctions have been used in the assessment of air transportation processes, specifically for slot allocation at airports (Button, 2008; Gruyer et al., 2004; Castelli et al., 2011; Pertuiset et al., 2014; Ball et al., 2018). However, there is a lack of literature on the use of auctions to analyse the procurement of subsidised routes.

The regions (items) in the procurement of air services substitute and/or complement each other: commonly, an air carrier can serve two regions with a one-stop service instead of the two regions individually. A combinatorial auction framework would allow the air carriers to bid for regions or bundles of regions based on their substitutability and complementarity. In this auction, the transportation authority is the buyer and the airlines are the sellers of air services. The purpose of the auction is for the transportation authority to select airlines that can provide air services along the subsidised routes and determine the subsidies to pay.

In practice, a single-round (sealed-bid) form of the combinatorial auction is used: it begins with the transportation authority defining the originating (remote) regions in need of subsidised air services to improve people's accessibility to certain destinations. Airlines prepare and submit bids for subsets of regions-also referred to as bundles.

A formulation of a single-round combinatorial auction framework for subsidised routes should include two sub tasks: (1) preparation and submission of bids by the airlines, and (2) the determination of winners by transportation authorities. These tasks can be formulated as two optimisation models that simulate the whole bidding process.

First, the preparation of bids by the airlines can be formulated as an optimisation model. Although, the airlines naturally aim to maximise profits, 
taking into account the available demand and their capacity (e.g., number of aircraft), this does not necessarily result in the minimisation of the required subsidies, which is the criteria used by the transportation authority to determine the winning airlines. An airline that wishes to win the auction should prepare bids that minimise the subsidies while considering a reasonable profit threshold ${ }^{1}$. Thus an optimisation model that replicates the behaviour of airlines when preparing bids for subsidised routes should simultaneously capture these two objectives of the airlines and the transportation authority. Given all the regions $r$ specified in the auction by the transportation authority, the airline can submit bids for all possible bundles of regions by solving an optimisation model for each possible bundle by considering the available demand, its capacity (e.g., total aircraft seats), reasonable profit threshold, and requirements on the minimum number of daily return flights and the maximum airfare. For all regions in a bundle, the airline considers non-stop and one-stop routes $l$ to provide air services to the different regions through the respective airport $a$. A base model that replicates the preparation of a bid for a given bundle by an airline has four components as presented in Table 3.2.

Table 3.2: Components of a base model for the preparation of a bid to serve regions in a bundle

\begin{tabular}{|c|c|}
\hline 1. Objective: & Minimise the total subsidies for serving the regions in a bundle \\
\hline 2. Decision variables: & $\begin{array}{l}\text { The total subsidies }(s) \text {. } \\
\text { The number of daily return flights per route }\left(f_{l}\right) \text {. } \\
\text { The one-way airfare }\left(P_{a}\right) \text { for routes through airport } a \text {. }\end{array}$ \\
\hline 3. Input parameters: & $\begin{array}{l}\text { The total operation cost per return flight along route } l\left(c_{l}\right) \text {. } \\
\text { The potential demand at airport } a \text { for each route } l \text {. } \\
\text { The maximum one-way airfare for routes through } \\
\text { airport } a\left(P_{a}^{\max }\right) \text { if applicable. } \\
\text { The minimum number of daily flights }\left(f^{\min }\right) \text { if applicable. } \\
\text { The minimum profit threshold. }\end{array}$ \\
\hline 4. Constraints: & $\begin{array}{l}\text { The airline makes a minimum profit. } \\
\text { The served demand at airport } a \text { for each route } l \text { is determined } \\
\text { by the airfare, travel time and number of flights. } \\
\text { The served demand should not exceed the airline's capacity. } \\
\text { The selected airfare should should not exceed the } \\
\text { maximum airfare } P_{a}^{\max } \text {. } \\
\text { The required minimum daily return flights } f^{\min } \text { are satisfied. } \\
\text { A bid is submitted for a bundle if all regions can be served. }\end{array}$ \\
\hline
\end{tabular}

Second, the determination of winners can be formulated as a Weighted Set Partitioning Problem. Each airline submits bids for all possible bundles. (e.g., using a model such as described in Table 3.2). Each bundle $j$ has a price $p_{j}=s$, which is the total subsidy that the airline requires to provide air services to all regions in that bundle. The transportation authority selects

\footnotetext{
${ }^{1}$ The profit threshold, that is, the airline's opportunity cost is defined as the ratio between operating profits and revenues (return on revenues).
} 
the bids that minimise the subsidies. The model for the determination of winners has the four components presented in Table 3.3.

Table 3.3: Components of a base model for the determination of winners by transportation authorities

\begin{tabular}{ll}
\hline 1. Objective: & Minimise the total subsidies \\
2. Decision variables: & $x_{j}=1$ if bundle $j$ is selected, 0 otherwise. \\
3. Input parameters: & $\begin{array}{l}\text { Price } p_{j} \text { of bundle } j . \\
d_{a j}=1 \text { if bundle } j \text { has a bid from airline } a, 0 \text { otherwise. } \\
a_{r j}=1 \text { if region } r \text { is in bundle } j, 0 \text { otherwise. }\end{array}$ \\
& $\begin{array}{l}\text { Every region is allocated to exactly one airline. } \\
\text { 4. Constraints: }\end{array}$ \\
& All regions are served.
\end{tabular}

Concerning the preparation of bids, the combination of social-welfare analysis and optimisation provides a sound and objective basis for setting the requirements for subsidy schemes. J. P. Pita et al. (2013) proposed an integrated flight-scheduling and fleet-assignment model for airlines to determine the subsidised routes to operate, that minimises the total social cost given a certain demand. Although they had a model that minimised total social cost, they also admitted that maximising social welfare could be a more relevant objective. A later study by J. Pita et al. (2014) focused on using a socially-oriented integrated flight-scheduling and fleet-assignment optimisation model to assess different the level of service requirements for subsidy schemes. To enable the analysis of the impact of certain requirements on the subsidies and social welfare, our base model in Table 3.2 was modified, by relaxing some of the constraints, for example, the requirement for maximum airfare at each airport. Additionally, the passenger demand was able to capture changes in supply, for example, travel time and number of flights, which would improve model accuracy.

\subsection{Required Data}

The decision support models for procuring subsidised routes require various parameter/input data for implementation: the subsidised route network in Sweden was used as a case study. The required data were categorised into two: (1) available data, and (2) estimated data.

The available data are accessible either in published or unpublished form from sources such as websites, reports, and databases. These include:

- The data on population (e.g., location/centre longitude and latitude, number of people at a given centre). 
- The data on population (e.g., location/centre longitude and latitude, number of people at a given centre).

- Data on the current subsidised routes in Sweden, for example, the regions considered and the corresponding airports, the used accessibility criteria and travel time targets, and tender requirements such as the minimum daily number of flights per route, the maximum airfare per region/airport.

- Historical data on the demand, average airfare, and number of flights along the current subsidised routes.

- The data on airports, from which all possible flight routes (including the current subsidised routes) can be generated.

- The ground travel time for both private cars and public transportation; the flight times.

- The historical data about the current subsidised routes such as operation cost for the used aircraft types.

On the other hand, estimated data are not readily available and should be obtained using estimation models, such as statistical models. Estimated data is required when other possible routes-not the current routes-are considered. These data include: the route subsidy cost, the route operation cost per flight, the demand at a given airport $a$ along route $l$, and the minimum profit threshold. The route subsidy cost was estimated based on the route revenues and the route operation cost. The demand can be estimated based on the population, airfare, and total travel time (i.e., sum of ground travel time and flight time). The route operation cost can be estimated based on the used aircraft seating capacity and the great circle distance in kilometres.

\subsection{Output of the Decision Models}

The decision models assist the transportation authorities with the first two stages of the procurement (see Figure 2.1) for subsidised routes but the model results would still require assessment before the last stage, that is the implementation of the subsidy scheme. The output of the models include a (suggested) network of subsidised routes, the number of people that can access certain destinations, the airlines to serve these routes, the amount of required subsidies. For each route, the results also include the number of flights, airfare, and the corresponding number of passengers. The transportation authorities can assess these results from the perspectives of all the three stakeholders-the airlines, the transportation authority, and the passengers-usually focusing on changes relative to the current subsidised 
routes. From the the airlines' perspective, the changes in profits are of interest while from the transportation authority's perspective, the changes in the amount of subsidies to be paid are of interest. From the passengers' perspective, the results can be assessed by two measurements: (1) changes in accessibility i.e., the number of people with improved accessibility to a given destination, and (2) the changes in consumer surplus, which is the difference between what the passengers are willing to pay in terms of travel costs (travel time, airfare, etc.) and what they actually pay. Consumer surplus can capture changes in consumer welfare due to changes to subsidised routes, changes in time travel, changes in airfare, and changes in the number of passengers. 


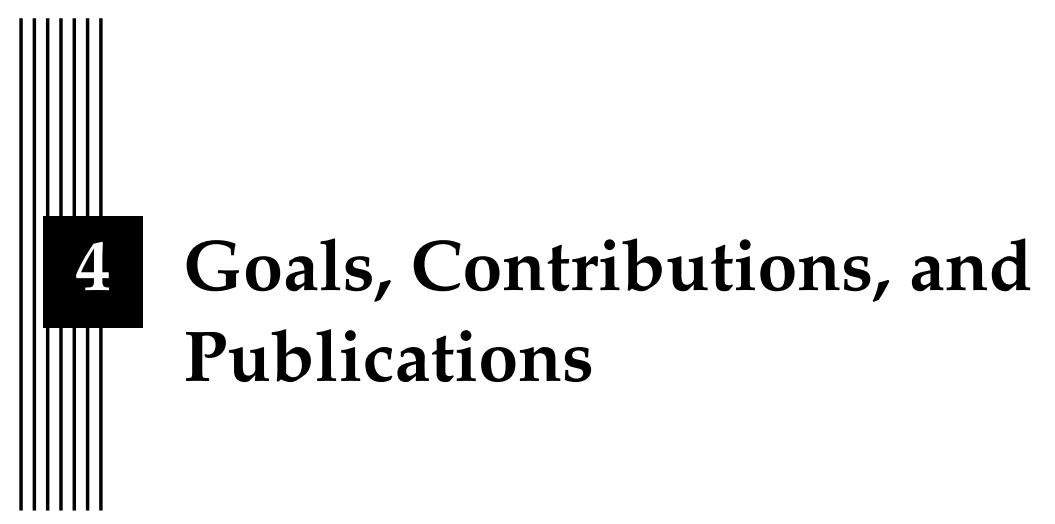

\subsection{Research Questions and Goals}

The overall aim of this thesis is to design decision support models that can be used by transportation authorities to select routes to subsidise and to design auctions for selecting airlines to serve these routes. The aim covers the two main tasks when procuring subsidised flights, i.e., investigating the need for a subsidy scheme and the tendering process for selecting airlines to serve subsidised routes, which lead to two research questions:

1. How to model the selection of routes to subsidise?

2. How to model an auction that replicates the selection of the airlines to serve subsidised routes?

This work addresses the research questions with two goals:

1. To develop a model that can compare existing and non-existing subsidised schemes, and can objectively select an optimal set of subsidised routes.

2. To develop a model that can help the transportation authorities choose appropriate tendering requirements by studying how changes in these requirements may affect the subsidies, the airlines and the passengers. 


\subsection{Contributions}

We achieve the goals in Section 4.1 with the following contributions. We:

1. Develop a budget-constrained optimisation model that selects an optimal set of subsidised routes from all possible routes based on given accessibility criteria.

2. Propose a method to estimate the subsidies of new routes. This makes it possible to assesses all the possible subsidised routes.

3. Develop an integrated auction framework for the tendering process of subsidised routes.

4. Develop a bid-preparation model as an optimisation model that is specific to subsidised routes, to represent the airlines' behaviour in the auction framework. The bidding airline is interested in minimising the subsidies subject to a target profit threshold.

5. Propose a method to estimate the demand, which is appropriate for the origin-destination markets in subsidised schemes.

6. Estimate the route operation cost for the small aircraft types that typically operate subsidised routes. A model based on the small aircraft types-used to operate the subsidised routes-gives a more accurate cost estimate than a model based on bigger aircraft types, which are more appropriate for commercially viable routes.

7. Demonstrate the application of the models using the Swedish subsidy scheme as a case study and suggest policy guidelines.

\subsection{Summary of the Papers}

In this chapter, we summarise the papers-attached at the end of this workwhere we address the aims of this work: Aim 1 in Paper I, and Aim 2 in Paper II.

\subsubsection{Paper I - Decision Support for an Optimal Choice of Subsidised Routes in Air Transportation}

Paper I answers research question 1, i.e., How to model the selection of routes to subsidise? The aim of this paper was to describe a mathematical model that assists decision-makers in selecting the optimal network of subsidised routes in air transportation, subject to defined accessibility criteria (e.g., accessibility to a major city, to advanced healthcare, or to an international airport) and a budget. Specifically, we formulated the problem of selecting the routes to subsidise as a budgeted maximum coverage model that 
is capable of maximising multiple objectives corresponding to different accessibility criteria. Additionally, we also presented a method to estimate the cost of subsidising new routes because this is unknown until the auction process is carried out.

We used Sweden as a case study and explicitly modelled two of the criteria used by Trafikverket (The Swedish transport Administration), i.e., accessibility to capital city-Stockholm, and accessibility to an international airport, within 4 hours and 5 hours of total travel time. The total travel time included a combination of ground travel time and flight time (if needed). As subsidised routes aim to improve accessibility of remote regions to certain destinations, the current subsidised routes were compared to the optimal network of subsidised routes suggested by the model using the number of people with improved accessibility. We also considered a scenario where an airport is closed to further illustrate how the model also can be used to make airport location decisions.

The results showed that: (1) although most of the Swedish population already has good accessibility (i.e., either by ground transportation to the final destination or by a combination of ground transportation to the airport, a commercial flight to the final airport and possibly ground transportation from the airport to the final destination), the model can suggest new routes that could further improve accessibility without increasing the subsidisation cost, and (2) the closure of an airport reduces the number of commercial routes, which would reduce the accessibility to a given destination; a subsidised route would hence be required as a replacement. The ability of the model to consider several accessibility criteria makes it useful for decision makers at transportation authorities.

This paper was co-authored with Tobias Andersson Granberg, Valentin Polishchuk, and Clas Rydergren. The author of this thesis is the main author of this paper and contributed to the formulation and implementation of the model, collection and processing of the data, and writing of the manuscript.

Paper I is published in the Journal of Air Transport Management (Kinene, Granberg, Polishchuk, et al., 2020).

\subsubsection{Paper II - Using an Auction to Analyse the Tendering of Subsidised Routes in Air Transportation}

Paper II answers research question 2, i.e., How to model an auction that replicates the selection of the airlines to serve subsidised routes? In Paper II, we developed an integrated auction framework to provide decision support to transportation authorities when designing tendering processes for subsidised routes. The framework includes two main models. First, the winner determination problem, which is used to select the bids with the minimum subsidies. Second, the bid preparation model, which replicates the airline's behaviour when preparing bids for subsidised routes. Additionally, we pro- 
posed models to estimate the appropriate demand and the route-operation cost for subsidised routes, which are needed as input to the bid preparation model.

We demonstrated the usefulness of the auction framework with an application to the network subsidised routes in Sweden as a case study. The subsidised routes in Sweden, similar to other subsidised routes, are often criticised due to inefficiencies and excessive subsidies, which result from restrictions defined by transportation authorities during the tendering process, e.g., maximum airfare and minimum number of daily flights. We suggested policy guidelines for how to set these requirements in the tendering process by assessing scenarios with and without two requirements-the maximum airfare and the minimum number of daily flights. The results were analysed based on the total social welfare, that is, the consumer surplus from the passengers, the airline profits, and government subsidies.

Our analysis revealed that from the government's perspective of minimising subsidies, having no restriction on both the airfare and the number of flights is the best way to design the tendering process. However, having only a requirement on the maximum airfare is better for both the consumers and the government.

This paper is co-authored with Tobias Andersson Granberg, Sebastian Birolini, Nicole Adler, Valentin Polishchuk, and Jean-Marie Skoglund. The author of this thesis is the main author of this paper and has contributed to the formulation and implementation of the model, collection and processing of the data, and writing of the manuscript.

Paper II is submitted to TBD.

\subsection{Discussion and Future Research}

The procurement of subsidised routes typically starts with the selection of routes to subsidise followed by an auction where the transportation authority selects the airlines to provide air services along these routes. In this thesis, we develop two decision support models that can be used by transportation authorities for the procurement of subsidised routes, specifically to select the routes to subsidise and to design auctions with appropriate requirements for these routes.

The transportation authorities usually select the routes to subsidise using accessibility criteria based on travel time and the proportion of the population served. The selected routes are constrained by a limited budget, which should also be considered. During the selection of routes to subsidise, the transportation authorities have incomplete information about the subsidies required by the airlines that eventually provide air services along subsidised routes. Using historical data on existing subsidised routes hinders the evalu- 
ation of other possible routes. Therefore, a model for estimating the subsidies required of all possible routes is necessary for the consideration of an aspect of a limited budget to the selection of subsidised routes. We demonstrate that a decision support model for selecting the routes to subsidise leads to improved accessibility to given destinations (e.g., the capital and an international airport), the possibility to reduce subsidy cost compared to the current network of subsidised routes.

The auction for subsidised routes has three steps: (1) auction definition by the transportation authority, (2) bid preparation by the bidding airlines, and (3) winner determination by the transportation authority. The auction definition includes the selected routes to subsidise and the corresponding requirements (e.g., maximum airfare and minimum number of flights), which affects how the airlines prepare bids for subsidised air services, the characteristics selected bid such as the total required subsidy and consumer surplus. We have modelled the auction for subsidised routes as an integrated framework of two models representing the last two steps because Step 1 is usually given information. The airlines submit bids indicating the subsidies required to provide air services to one or combinations of the subsidised routes. We demonstrate that an auction framework can be used to design auctions with appropriate requirements for tendering process of subsidised routes. Appropriate tendering requirements can lead to the reduction of subsidy cost and improvement in consumer surplus compared to the current network of subsidised routes.

Different from the first task of the procurement of subsidised routes (i.e., the selection of routes to subsidise) where the transportation authorities have incomplete information about the required subsidies, the auction helps the transportation authority to determine the subsidies to be paid. During the auction, the airline uses its estimates of revenue and the route-operation cost to determine the required subsidies. Although the current practice is to have the first step of the auction process (i.e., auction definition) after the selection of routes to subsidise, the incomplete information faced by the transportation authorities when selecting the routes to subsidise may lead to sub-optimal results. For example, the selected routes in the first task may not provide the best benefits for the consumers during the second task (i.e., auction).

As future research, various directions can be considered. One possible future direction is to solve the two tasks of the procurement of subsidised routes simultaneously instead of separately as it is the currently done in practice. This could be done by providing iterative feedback between the two tasks based on their relationships. The could solve the issue of having sub-optimal results as a consequence of sequentially solving the two tasks. Another direction is to have an enhanced flight-scheduling component in the bid preparation model, incorporating both detailed fleet assignment and tail routing. Flight-scheduling would better capture the demand-supply relationship, for example the response of demand to the number of flights. It 
may also be appropriate to incorporate schedule delay (a difference between a desired arrival or departure time and the actual time) in the flight scheduling. The emergence of electric aircraft and flying taxis should be explored by future research. These aircraft are initially expected to be quite small with a limited range, which is suitable for subsidised routes with low demand. The electric aircraft are expected to require less subsidies due to the lower operation cost than the currently used traditional aircraft. However, transportation authorities may have to re-design subsidised routes as multi-stop routes to accommodate the limited range. 


\section{Bibliography}

Anger, Göran, Johan Holmér, and Pär-Erik Westin (2016). "Experience of PSO and the Tendering Process in Sweden". In: Air Transport Provision in Remoter Regions. Routledge, pp. 137-168.

Ball, Michael O, Frank Berardino, and Mark Hansen (2018). "The use of auctions for allocating airport access rights". In: Transportation Research Part A: Policy and Practice 114, pp. 186-202.

Biswas, Shantanu and Y Narahari (2005). "Iterative dutch combinatorial auctions". In: Annals of Mathematics and Artificial Intelligence 44.3, pp. 185-205.

Button, Kenneth (2008). "Auctions-what can we learn from auction theory for slot allocation?" In: Airport Slots-International Experiences and Options for Reform. Ashgate (2008), pp. 291-309.

Castelli, Lorenzo, Raffaele Pesenti, and Andrea Ranieri (2011). “The design of a market mechanism to allocate air traffic flow management slots". In: Transportation research part C: Emerging technologies 19.5, pp. 931-943.

Dahlström, Amanda, Malin Ekeström, Malin Lokrantz, and Jean-Marie Skoglund (2018). Upphandling av flygtrafik i Sverige. Tech. rep. Transportstyrelsen.

DoT U.S. (2009). “What is Essential Air Service (EAS)". In: Office of aviation analysis, US Department of Transportation.

EU Regulation (2008). “No 1008/2008 of the European Parliament and of the Council of 24 September 2008 on common rules for the operation of air services in the Community(Recast)". In: EC, and amending Regulation (E. Luxembourg: Official Journal of the European Union, 31 October 2008, L293. 
Fageda, Xavier, Ancor Suárez-Alemán, Tomás Serebrisky, and Reinaldo Fioravanti (2018). "Air connectivity in remote regions: A comprehensive review of existing transport policies worldwide". In: Journal of Air Transport Management 66, pp. 65-75.

Flynn, John and Samuel Ratick (1988). "A multiobjective hierarchical covering model for the essential air services program". In: Transportation Science 22.2, pp. 139-147.

Gössling, Stefan, Frank Fichert, and Peter Forsyth (2017). "Subsidies in aviation". In: Sustainability 9.8, p. 1295.

Gruyer, Nicolas and Nathalie Lenoir (2004). "Allocating airport slots: a combinatorial auction mechanism". In:

Kinene, Alan, Tobias Andersson Granberg, Sebastian Birolini, Nicole Adler, Valentin Polishchuk, and Jean-Marie Skoglund (2021). "Using an Auction to Analyse the Tendering of Subsidised Routes in Air Transportation". In: Submitted to TBD.

Kinene, Alan, Tobias Andersson Granberg, Valentin Polishchuk, and Clas Rydergren (2020). "Decision Support for an Optimal Choice of Subsidised Routes in Air Transportation". In: Journal of Air Transport Management 82, p. 101724.

Lian, Jon Inge, Harald Thune-Larsen, and Lars Draagen (2010). Evaluering av anbudsordningen for regionale flyruter. Transportøkonomisk institutt.

Litman, Todd (2020). "Evaluating Accessibility for Transport Planning". In:

Matisziw, Timothy C, Chieh-Lung Lee, and Tony H Grubesic (2012). "An analysis of essential air service structure and performance". In: Journal of Air Transport Management 18.1, pp. 5-11.

McAfee, R Preston and John McMillan (1987). "Auctions and bidding". In: Journal of economic literature 25.2, pp. 699-738.

Milgrom, Paul R and Robert J Weber (1982). "A theory of auctions and competitive bidding". In: Econometrica: Journal of the Econometric Society, pp. 1089-1122.

Mochón, Asunción, Yago Sáez, et al. (2015). Understanding auctions. Springer.

Morrison, Steven and Clifford Winston (2010). The economic effects of airline deregulation. Brookings Institution Press.

Novack, Robert A and Stephen W Simco (1991). "The industrial procurement process: a supply chain perspective". In: Journal of Business Logistics 12.1, p. 145.

Pertuiset, Thomas and Georgina Santos (2014). "Primary auction of slots at European airports". In: Research in Transportation Economics 45, pp. 66-71.

Pikovsky, Alexander (2008). "Pricing and bidding strategies in iterative combinatorial auctions". PhD thesis. Technische Universität München.

Pita, João, Nicole Adler, and António Antunes (2014). "Socially-oriented flight scheduling and fleet assignment model with an application to Norway". In: Transportation Research Part B: Methodological 61.2, pp. 17-32. 
Pita, João P, António P Antunes, Cynthia Barnhart, and António G de Menezes (2013). "Setting public service obligations in low-demand air transportation networks: Application to the Azores". In: Transportation Research Part A: Policy and Practice 54, pp. 35-48.

Trafikverket (2013). Flygutredning 2015-2019. Tech. rep. Trafikverket.

- (2017). Flygutredning 2019-2023. Utredning inför beslut om allmän trafikplikt. Tech. rep. Trafikverket.

Vickrey, William (1961). "Counterspeculation, auctions, and competitive sealed tenders". In: The Journal of finance 16.1, pp. 8-37.

Vijay, Krishna (2015). Understanding auctions. San Diego: Academic.

Williams, George and Svein Bråthen (2012). Air Transport Provision in Remoter Regions. Ashgate Publishing, Ltd.

Williams, George and Romano Pagliari (2004). "A comparative analysis of the application and use of public service obligations in air transport within the EU". In: Transport Policy 11.1, pp. 55-66. 



\section{Papers}

The papers associated with this thesis have been removed for copyright reasons. For more details about these see:

http://urn.kb.se/resolve?urn=urn:nbn:se:liu:diva-173222 


\section{FACULTY OF SCIENCE AND ENGINEERING}

Linköping Studies in Science and Technology, Licentiate Thesis No. 1898, 2021 Department of Science and Technology (ITN)

Linköping University

SE-581 83 Linköping, Sweden

www.liu.se

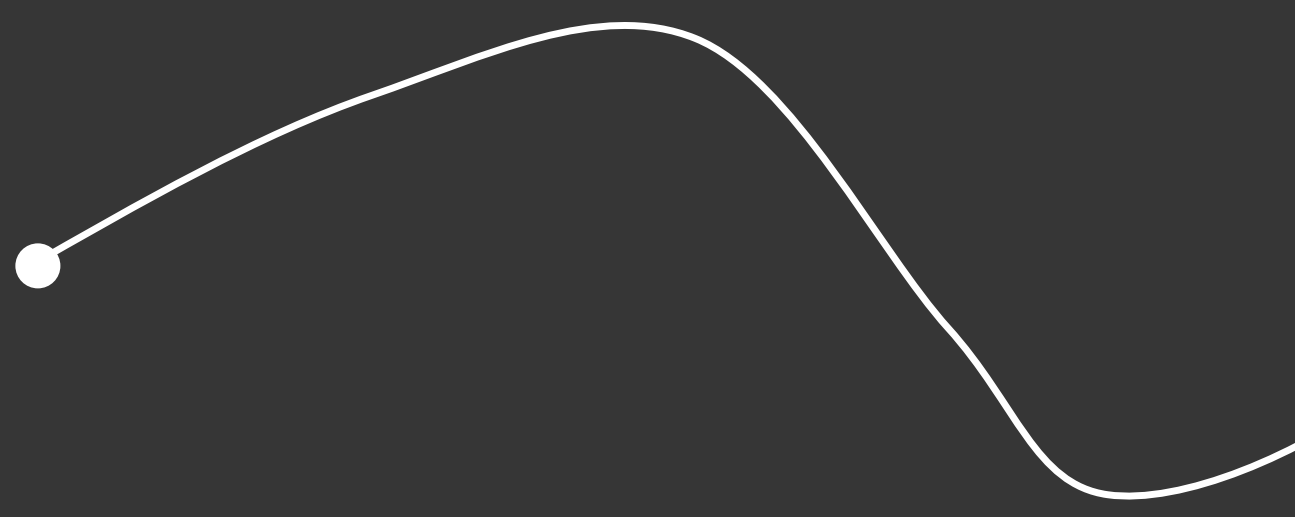

